\title{
THE RESISTANCE OF STEELS TO ABRASION BY SAND
}

\author{
By Samuel J. Rosenberg
}

\section{ABSTRACT}

A study has been made of the adaptability of three types of apparatus, namely, the ball-mill, the sand blast, and the Brinell machine, to the testing of the resistance of metals to abrasion. A detailed description of all apparatus used is given.

The ball mill was generally unsatisfactory; the sand blast gave consistent results but did not differentiate between the materials tested, apparently because of the fact that the abrading conditions were not sufficiently severe; but the Brinell machine proved to be generally satisfactory.

The Brinell test showed that the resistance to wear of normalized, annealed, hardened, or tempered carbon steels increases with their hardness. Increasing the temperature of annealing resulted in a slight increase in resistance to wear, the increase being more marked in a low-carbon than in a high-carbon steel.

Abrasion in this type of test is caused by the gradual breaking up of the individual grains and not by the removal of separate grains in their entirety, and this action is accompanied by local strain hardening.

\section{CONTENTS}

II. Previous investigations..

III. Equipment and test methods

1. Ball-mill test

2. Sand-blast test.

3. Brinell test...... 557

IV. Results _... 558

1. Ball-mill test Sand-blast test.

3. Brinell test.

(a) Selection of sand..... 564

(b) Effect of pressure and of distance traveled by disk $\quad 566$

(c) Effect of carbon content on resistance to wear....- 567

(d) Effect of tempering temperature on resistance to wear $\quad 569$

(e) Effect of annealing temperature on resistance to wear $\quad 569$

(f) Relation of hardness to resistance to wear ....... 572

(g) Examination of abraded surfaces_.......... 572

V. Discussion of results

1. Ball-mill test

3. Brinell test. 573

VI. Summary and conclusions

VII. Acknowledgments..._. 574

\section{INTRODUCTION}

The problem of testing the resistance of metals to wear is one of the most perplexing problems confronting the testing engineer to-day. So many different variables enter, that it is generally agreed there is no universal test for determining the resistance of metals to wear. Attempts have been made, therefore, by various investigators, to study certain types of wear with machines especially designed to $4754^{\circ}-30-4$ 
simulate particular conditions of service, and this method seems to be the most promising mode of attack.

The object of this investigation was not to find a universal testing machine for all conditions of service, because the development of such a machine does not appear to be probable, but it was believed that closely controlled laboratory tests with a series of ferrous metals would be of value as a contribution to the general problem of the testing of the resistance of metals to abrasion.

Wear may be divided into two major types-wear caused by abrasion of metal on metal, and wear caused by abrasives on metal. The latter type only will be considered in this paper.

\section{PREVIOUS INVESTIGATIONS}

Probably the earliest work on abrasive wear was carried out by Robin. ${ }^{1}$ His tests consisted in determining the wear of steels when rubbed under a known pressure on papers which were covered with an abrasive powder. A cylindrical steel specimen (50 $\mathrm{mm}$ in diameter) described a circular path having a diameter of $150 \mathrm{~mm}$; the pressure used was $1 \mathrm{~kg} / \mathrm{cm}^{2}$, and the speed was 70 revolutions per minute. The abrasion number was the sum of the weights of metal lost by abrasion in three consecutive tests, each lasting a minute.

For the same type of steel with the same abrasive, two sheets of different papers gave comparable results. Precision was from 2 to 10 per cent on ordinary steel and from 15 to 20 per cent for very hard steels. The effect of variables was stated to be as follows:

Pressure-Augments the wear approximately proportionately if within 0.5 to $2 \mathrm{~kg} / \mathrm{cm}^{2}$. In hard steels the wear increases at a more rapid rate and the curve is parabolic. The wear is proportional to the surface area of the specimen.

Speed.-Increases the abrasive power of the paper. Some steels are more sensitive than others, especially those which were also sensitive to variations in pressure.

Nature of abrasive.-Different abrasive materials and papers of different sizes of grain class the metals in approximately the same order while they give different figures as functions of the abrasive power.

Wear of steels. - In the case of annealed carbon steels, the wear is not proportional to the pearlite. A maximum of abrasion was found with 0.4 per cent carbon; in hypereutectoid steels the wear was approximately proportional to the carbon percentage. Increased fineness of the particles, cold work, and the presence of phosphorus increase the resistance to abrasion; the presence of silicon and manganese diminish it frequently. In cast metals the resistance grows with the phosphorus contents and with the percentage of iron carbide. The hardened steels can hardly be distinguished by this process; on the contrary, tempered steels lend themselves to this examination without any difficulty. The best resistance in hardened steels seems to be characteristic of the finest martensites.

The practical conclusions to be drawn for the domain of the science of testing are the following: Each mode of measurement and each kind of test leads to a special classification of the steels. The diverse modes of determining the wear can not be estimated by one and the same test. The test which has been explained so far appears only to lend itself for the examination of rails under certain special service conditions, to files, and to apparatus for disintegration, etc.

Brinell ${ }^{2}$ tested a variety of materials for resistance to wear using a machine designed by him and described elsewhere in this report. The effect of variables was stated to be as follows:

\footnotetext{
1 Felix Robin, The Wear of Steels With Abrasives, Carnegie Scholarship Memoirs, Iron \& Steel Inst., 2, p. 6; 1910. Also Abrasion Tests of Steol, Internat. Assoc. Test. Mats., Sixth Congress, III 6 ; 1912.

2 J. A. Brinell, An Investigation of the Resistance of Iron, Steel, and of Some Other Materials to Wear, Jernkontorets Annaler; 1921. A more convenient reference is the transcript, by H. A. Holz, Brinell's Researches on the Resistance of Iron, Steel, and Some Other Materials to Wear, Testing, 1, p. 104; 1924.
} 
1. Coarse-grained sand produces greater wear than finer sand under equal conditions.

2. In using pure quartz sand, wear is greater than that produced by ordinary sand.

3. Majority grain size of sand is of decisive influence as to abrasive action, therefore, two sorts of sand with equal size of smallest and largest grain may possess a widely different abrasive effect.

4. Grain form is not of influence, at least at pressures up to $10 \mathrm{~kg}$, but in the investigation of softer materials at lower pressures the sand with sharp corners produces a greater wear than sand of round grain.

In the carbon steels he found that resistance to wear increased with hardness.

A machine for the determination of abrasive wear was described by Parker. ${ }^{3}$ In making a test, the specimen was clamped with a definite force for a definite length of time against the face of an alundum grinding wheel, which was continuously dressed. The number of revolutions required to produce a given depth of wear was recorded automatically. The only results reported showed that of 3 materials, 1 untreated, 1 with a thin carburized case, and 1 with a thick carburized case, the last mentioned had the greatest resistance to wear, with the thin carburized case running a close second. The untreated material had a relatively low resistance.

A machine for determination of wear under wet grinding conditions was described by Blake. ${ }^{4}$ In principle, the machine was an accurately controlled grinding machine in which all conditions as to abrasive, pressure, speed, time, and moisture were under control. The wear was measured by the amount of metal worn off in approximately 15,000 feet of travel at a speed of 125 feet per minute, with a pressure of $50 \mathrm{lbs}$./in. ${ }^{2}$ on a testing face of approximately 3 square inches, and the wear was expressed as the ratio of loss of weight of the metal tested to loss of weight of an adopted standard (commercially pure iron). His conclusions are:

This abrasion tester has shown that each abrasive or mineral substance develops its own order of relative abrasion resistance for metals and that the position of any steel or alloy on a listing of abrasion factors will depend upon the nature of abrasive employed. In extreme cases it has been found that steels at the top of the list with one abrasive are at the bottom of the list with another. This discovery has eliminated the idea of securing general all-around high abrasion resistance in any one steel.

An actual service test was made by Clapp and Deveraux ${ }^{5}$ in which six 5-inch diameter chromium steel balls and six 5-inch diameter chromium-molybdenum steel balls were placed in a ball mill. The material ground was 3-inch maximum size chalcopyritic ore in which the gangue was a hard shale and quartz. After six weeks the chromium steel balls were 2 to $2 \frac{1}{2}$ inches in diameter while the others were 4 to $4 \frac{1}{2}$ inches in diameter.

\section{EQUIPMENT AND TEST METHODS}

\section{BALL-MILL TEST}

The mill used for this test consisted of two cylindrical containers which revolved about their longitudinal axes during test at a speed of $55 \mathrm{r} . \mathrm{p} . \mathrm{m}$. The interior of the container used in the tests (only

3 W. H. Parker, The Wearing Qualities of Tire Chains, Proc. Am. Soc. Test. Matls., 28-2, p. 332; 1928.

4 J. M. Blake, Wear Testing of Various Types of Steels, Proc. Am. Soc. Test. Matls., 28-2, p. 341; 1928.

$\checkmark$ E.IC. Clapp and F. C. Deveraux, Tests with Molybdenum Steel Balls at Matahambre, Cuba, Eng. \&

Min. J. Press, 120, p. 891; 1925. 
one container was used) was lined with rubber to prevent the impinging of the steel specimens upon the porcelain walls. After being so lined, the size of the container was 9 inches in diameter by 12 inches long. Figure 1 shows a photograph of the apparatus.

The specimens used for this test were ground and lapped into 1-inch spheres. Ten kilograms of a certain sand was placed in the mill at the beginning of each test run, the samples were then laid in the sand, the cover tightened, and the mill started. Entirely new

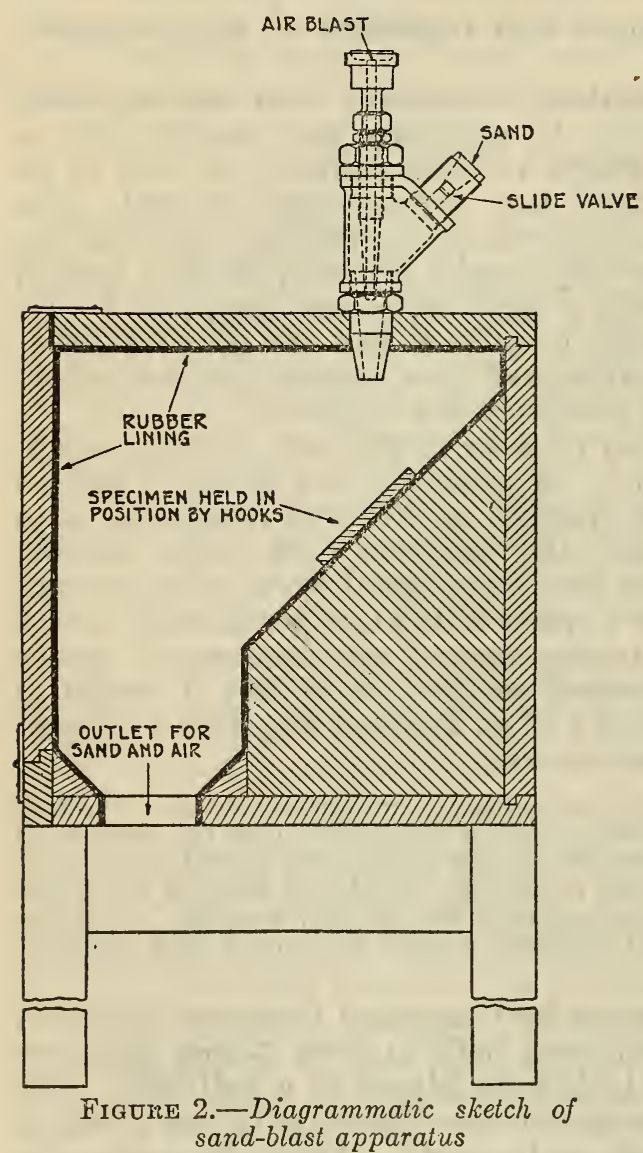
sand was used for each test. The diameters of the specimens were carefully measured and the losses of weight determined after each run. Wear was expressed as loss of weight (milligrams) per square centimeter of surface per hour of test.

\section{SAND-BLAST TEST}

Since the sand blast is such a rapidly abrading process, it seems logical to attempt to adapt it to abrasion testing. Figure 2 is a diagrammatic sketch of the apparatus designed and used for this test. In this test a special nozzle, five-sixteenths inch in diameter, was placed in the top of a rubber-lined wooden box. The nozzle was connected to the bottom of a $Y$ pipe fitting. Sand and air were introduced through the two upper branches of the $Y$, the air passing through an inner tube into the $Y$. The lower end of this tube, which carried the air blast into the nozzle, was below the point at which the sand was introduced so as to avoid "backing up" of the sand. The introduction of the sand was controlled by a slide valve.

The specimens used were flat, 3 -inch squares, about one-fourth inch thick, held in place at an angle of $45^{\circ}$ to the axis of the nozzle and about $3 \frac{1}{2}$ inches below it. An opening in the bottom of the box provided an outlet for the sand and air.

In all tests a weighed amount of sand was placed in the sand container. A rubber hose connected the bottom of this container with the sand inlet. The air blast was adjusted to the proper pressure, and a slide valve in the sand inlet was opened, thus giving an immediate and full flow of sand. The air blast, emerging from the tube, 
B. S. Journal of Research. RP214

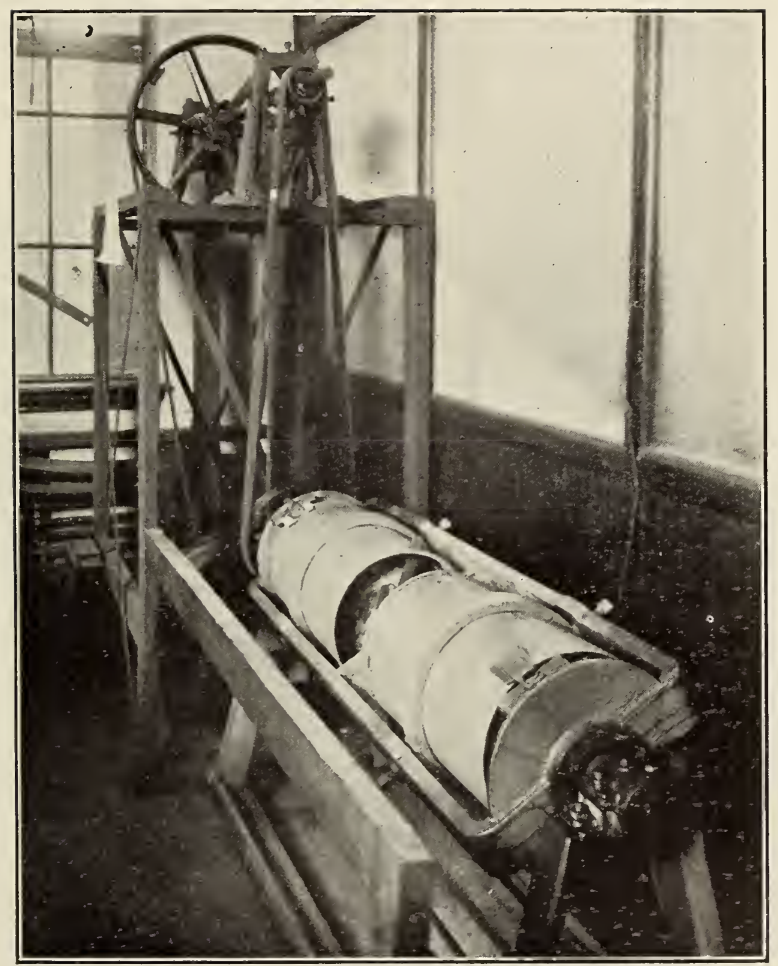

Figure 1.-Ball mill 
B. S. Journal of Research, RP214

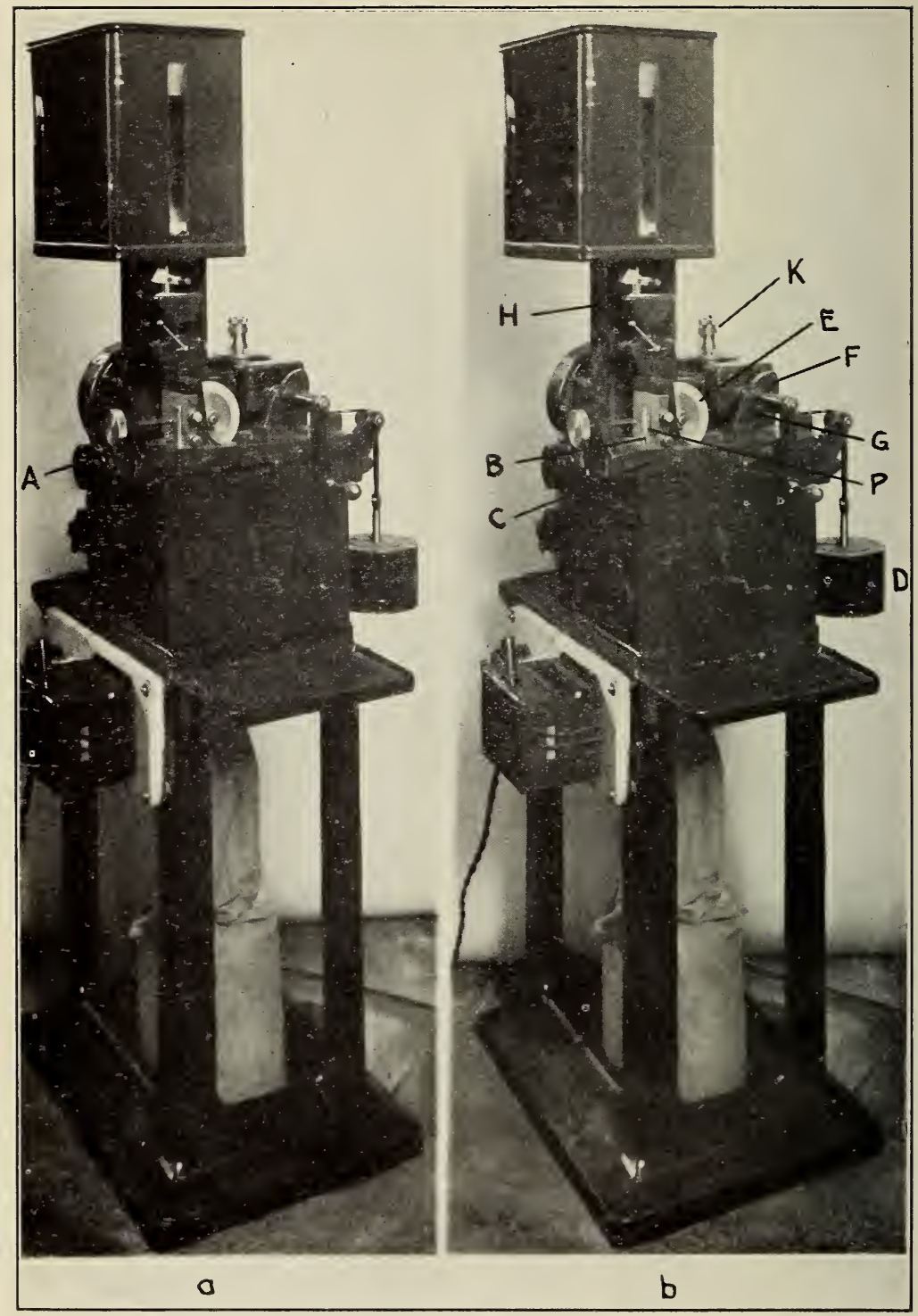

Figure 3.-Brinell machine

$a$, With specimen in position for test; $b$, with specimen removed. 
helped suck the sand downward and automatically caused mixture in the nozzle and abrasion of the specimen.

The specimens were cleaned and weighed before and after test, and the loss of weight taken as a measure of the resistance to wear. Several consecutive tests were made on each specimen until a definite rate of wear was observed.

\section{BRINELL TEST}

A photograph of the Brinell machine for testing the resistance of materials to wear, with and without a specimen in place, is shown in Figures $3(a)$ and $(b)$. In operating the machine, the specimen, $A$, was clamped to a siotted plate, $B$, mounted on a carriage, $C$, to which was attached a cord passing over a pulley and carrying the weights, $D$. A disk, $E$, of openhearth iron, $100 \mathrm{~mm}$ in diameter and $4 \mathrm{~mm}$ thick, was so mounted on a shaft that the center line of its face coincided with the center line of the slot, $B$, against which the specimen was clamped. When the cam, $F$, working against a stop, $G$, on the slide was turned to the proper position; the carriage, $C$, mounted on ball bearings, moved to the right until the specimen rested against the abrasion disk, the pressure between the two being determined by the weights attached to the end of the slide.

A hopper, $H$, above the slotted plate was filled with sand fed into it from the receptacle placed above. During the test a continuous stream of sand was passed between the specimen and the disk. The disk had a speed of 45 r. p. m., and the linear travel of a point on its circumference could be adjusted by a graduated wheel and lock nut, $K$, on top of the machine. After the disk had run the predetermined distance, the motor stopped auto-
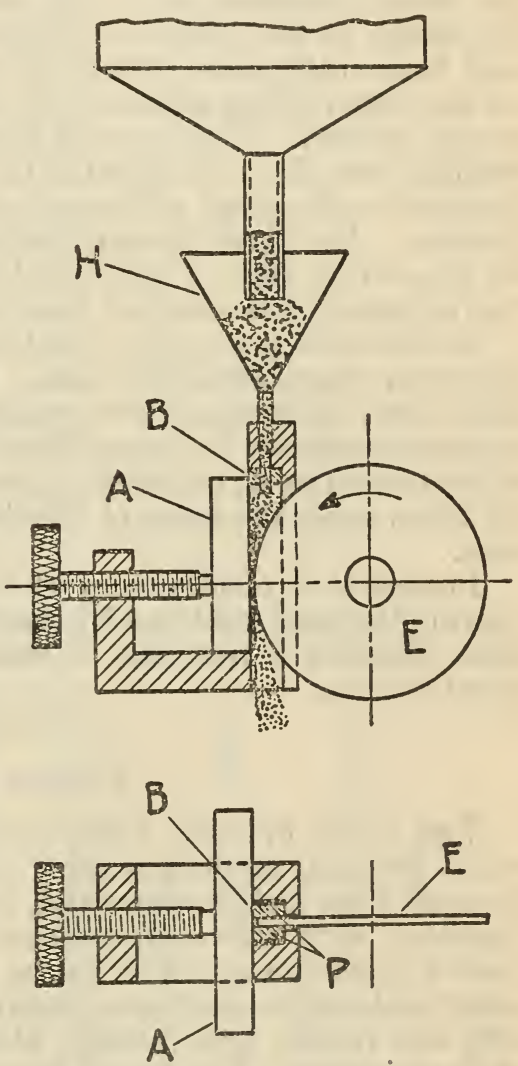

Figure 4.-Diagrammatic sketch of essential parts of Brinell machine

matically. During the test the motor also actuated a small fan which sucked the used sand down into a bag. Figure 4 is a diagrammatic sketch illustrating the essential parts of the machine.

The principle of the test, then, is as follows: The plane surface of the test specimen is pressed under a definite load against the edge of a slowly rotating disk while a constant stream of standardized, finegrained sand is fed between the surface of the disk and the specimen. After the circumference of the disk has run through the distance 
required for a test, the specimen is removed, washed, dried, and weighed, and the maximum depth of the segmentary groove produced is measured by means of a depth indicator reading directly to $0.01 \mathrm{~mm}$. The wear-resistance number " $\mathrm{Nm}$ " is calculated from the formula $N m=\frac{1,000}{A}$, where $A$ is the volume in cubic millimeters of the wornout segment for $1 \mathrm{~mm}$ thickness of disk. In tables furnished with the machine values of " $\mathrm{Nm}$ " are given for different values of diameter of disk and maximum depth of groove.

Two methods of expressing the resistance to wear as determined by the Brinell machine are (1) by means of the "Nm" numbers and (2) by means of the losses of weight. The former is rather unreliable and frequently gives erratic results, due to the difficulty of securing an accurate reading of the depth of the groove because of the relatively rough bottom. This error is aggravated by the human equation in reading the dial, the pointer of which wavers over an appreciable distance as the point of the gage is moved but slightly over the rough bottom. For these reasons, although the "Nm" numbers are given on the curves (figs. 9 and 13) the losses of weight have been used as the criterion of the rate of wear (or resistance to wear).

In the tests made, none of the abrading disks was used when its diameter wore below $97.5 \mathrm{~mm}$. When a new wheel was used for the first time, its surface was roughened by first running it against a dummy specimen in the machine. During a test the edge of the disk often burred over, especially when the test specimen was of soft steel. In these cases the faces of the disk were dressed by a file after each test.

Inconsistent results were at first obtained by this machine. By sieving the sand used and by removing the two guide plates, $P$ (fig. 4 ), thus allowing a free flow of sand, results were secured which gave good checks.

\section{RESULTS}

\section{BALL-MILL TEST}

Two series of tests were made. In one, standard Ottawa silica sand, 20 to 30 mesh, was used, while in the other, Illinois glass sand, a much finer and sharper sand, was used. The results of these tests, together with the compositions and heat treatments of the steels tested, are summarized in Tables 1 and 2 . All specimens marked " $\mathrm{C}$ " were cast, while specimens marked " $F$ " were forged. Widely different test results were usually obtained on the same material during different tests. The reason for this is not at all clear. 


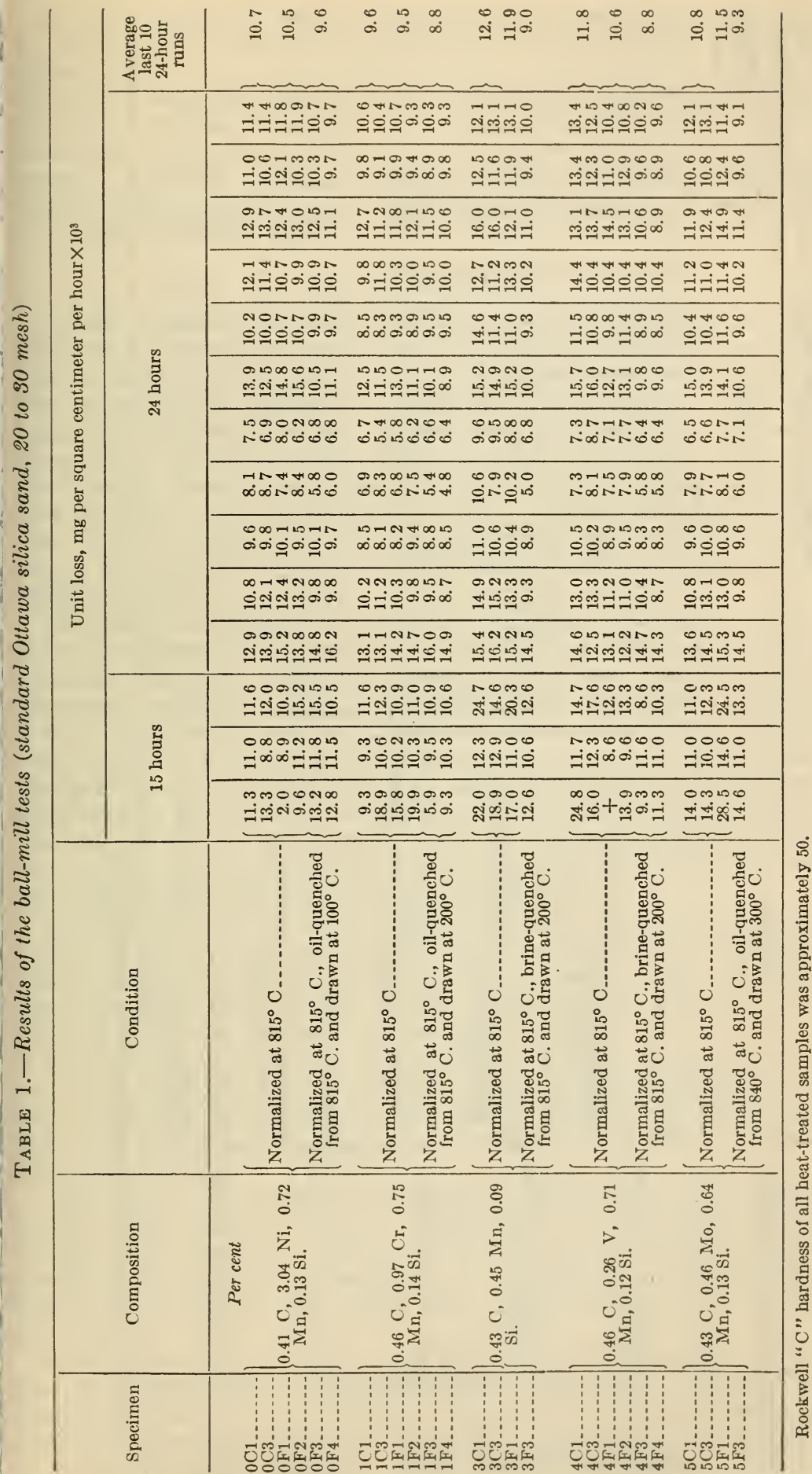




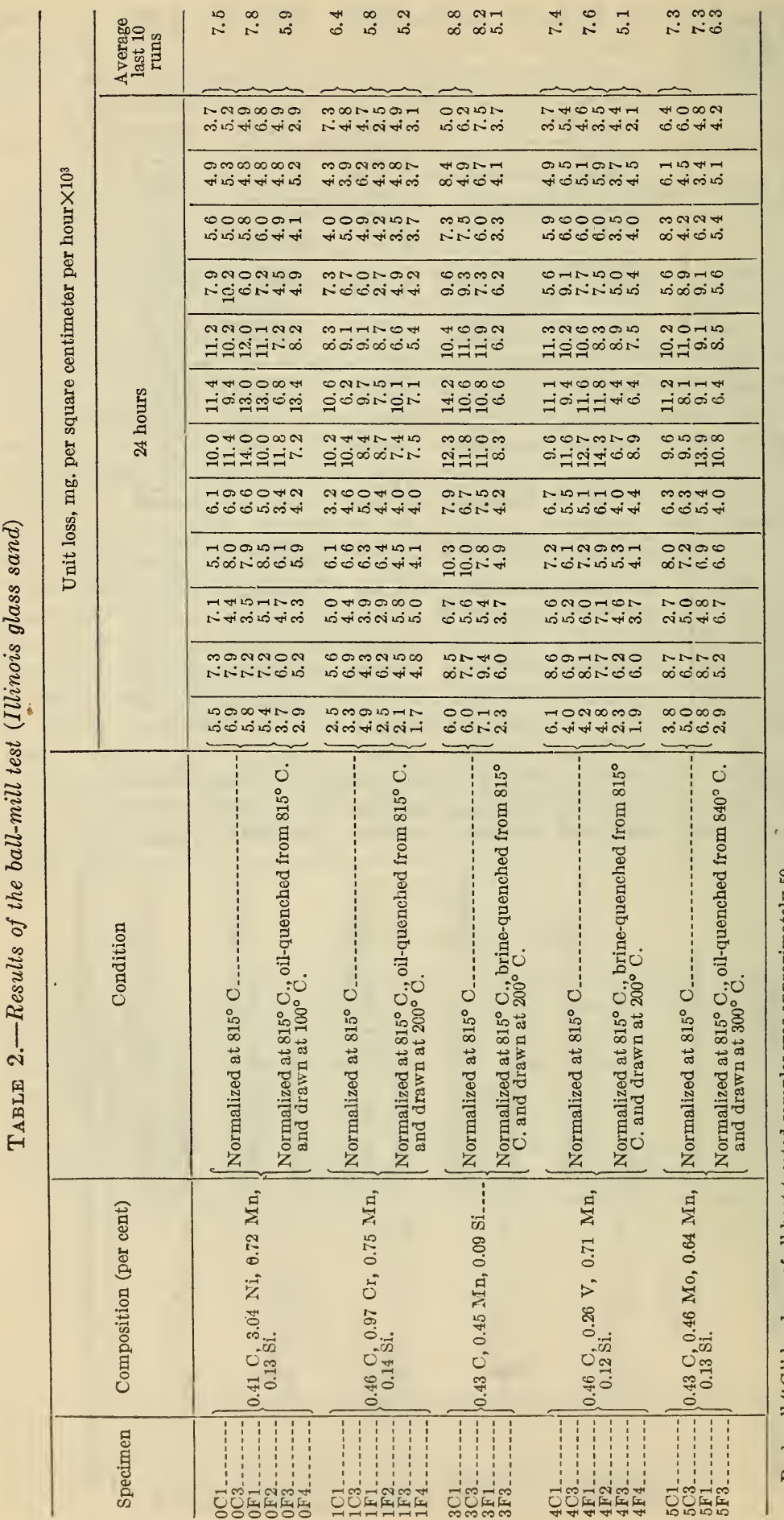


In order to obtain some idea of the trends shown by the tests, the last ten 24-hour runs with each abrasive were averaged. The differences between the various steels are not very marked. It is of interest to note that the forged and hardened specimens in each group lost the least amount of weight. Generally speaking, the 0.97 per cent chromium steel was found to be the most wear-resistant steel in the series. Contrary to what might have been expected, in this type of test the finer, sharper sand (Illinois glass sand) caused less wear than the rounded Ottawa sand.

\section{SAND-BLAST TEST}

Figure 5 shows the results of tests on a series of steels, together with the compositions and heat treatments. Plotting the losses of weight against the amount of sand blasted on the specimens gave, after a wearing-in period, a straight-line relationship. The loss of weight of the specimen per unit amount of sand blasted was determined from the slope of the line. It was surprising to note that all the different steels, even when subjected to different heat treatments, showed about the same rate of wear. The very slight increase in rate of wear shown by heats No. $85046 \mathrm{HM}$ and $68290 \mathrm{HM}$ was not due to the steel, but to the use of a new sand-blast nozzle, as will be explained later.

The results of tests on a series of 0.45 per cent carbon steels, to show the effects of additions of $\mathrm{Ni}, \mathrm{Cr}$, and $\mathrm{V}$ as alloying elements, are shown in Figure 6 . The sand used in these tests was different from the sand used for the tests summarized in Figure 5, therefore no obvious correlation between the two sets of curves is to be expected. Here, again, it was found that differences in composition and in heat treatment were not reflected by the resistance to wear, all steels showing the same rate of wear well within the limit of experimental error. The sand used in this test was standard Ottawa silica sand, 20 to 30 mesh in size, at an air pressure of $60 \mathrm{lbs} . /$ in. $^{2}$, and the loss of weight per $2 \mathrm{~kg}$ of sand blasted was about $0.095 \mathrm{~g}$.

Sand-blast tests on some widely different materials are summarized in Figure 7, both at 30 and $60 \mathrm{lbs}$. $/$ in..$^{2}$ pressure. The losses of weight when tested with the 30-pound pressure were considerably less than when tested under the 60-pound pressure, but the order of rates of wear was the same for the specimens.

In the tests under the 30-pound blast, no difference in resistance to wear was apparent between the two chromium-molybdenum steels, the 12 per cent manganese steel, and the white iron. Open-hearth iron showed a slightly higher loss of weight while gray iron lost considerably more.

The tests made under the 60-pound blast showed that there was no difference between the two chromium-molybdenum steels and the 12 per cent manganese steel. The white iron, however, showed a decidedly higher loss of weight, the open-hearth iron showed still more, and the gray iron again lost considerably more than any of the others.

It is apparent from the curves in the three figures just given that the sand-blast test is an extremely accurate test. As long as the same conditions of test existed, duplicate tests gave results which checked better than would be expected. The main variable difficult to control was the diameter of the sand-blast nozzle. This nozzle 


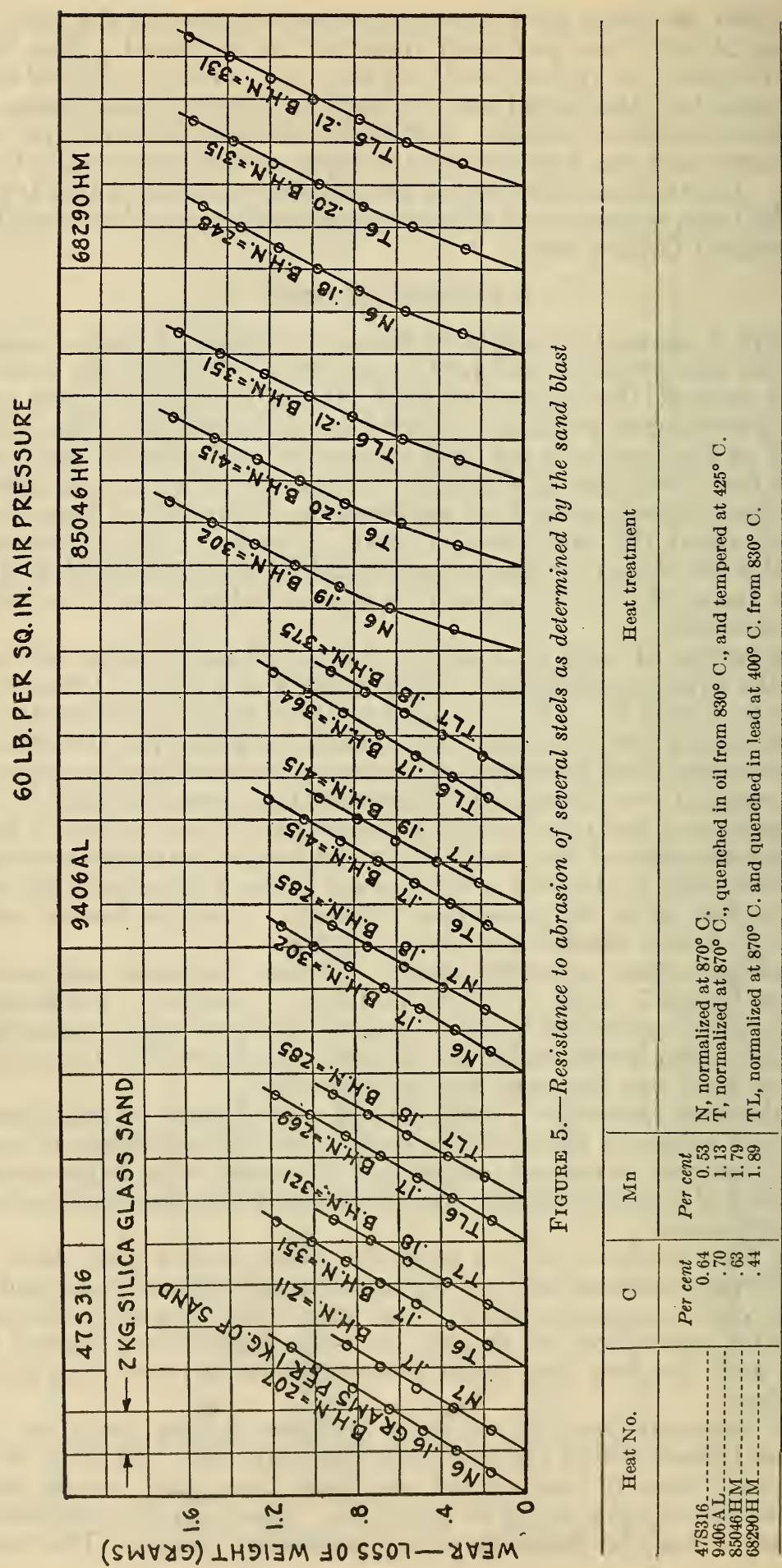


$\mapsto|1| \stackrel{2}{0}$ 覀|รุ| 风

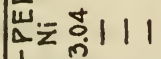

1

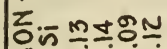

E tom กั้ก

然

$\sum_{a}$ 응=Nㅗㄴ

ग)

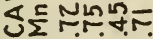

$\sum$

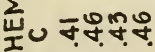
İ

菦些能年

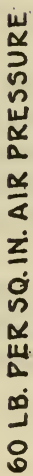
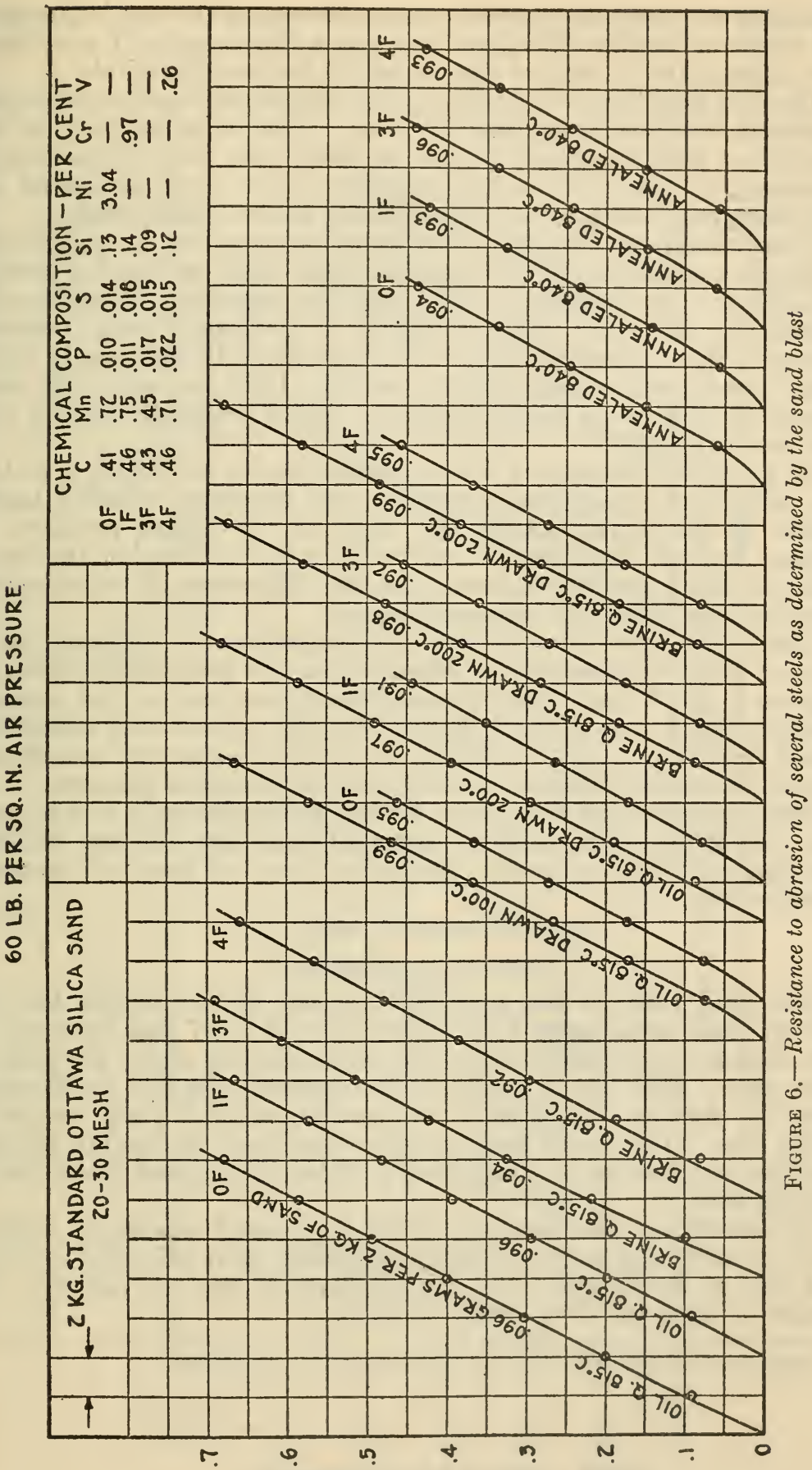

$\frac{\tilde{3}}{0}$

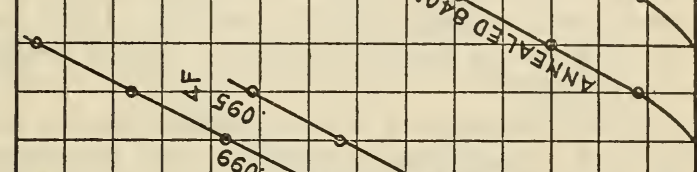

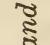

(2)

$\rightarrow$

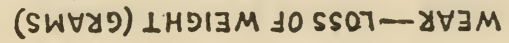


gradually wore and so enlarged, and as the area of the nozzle increased, the losses of weight of the test specimens decreased. It was, therefore, imperative to replace this nozzle at frequent intervals.

The fact that this test failed to differentiate between various steels indicated that sensitivity was lacking. It is probable that the test conditions used were not proper to bring out large differences in resistance to wear that may be inherent in the materials tested, and this reasoning is supported by a further study of the results.

If two materials, such as chilled iron and gray iron, be subjected to a light flow of sand under no pressure other than the force of gravity, it would not be surprising to find that one was about as resistant to abrasion as the other. As the velocity of the blast of sand increased, however, the chilled iron would begin to show its inherently higher abrasive-resistant qualities, and as the blast became still more severe, the difference between the two would probably become more and more apparent.

On applying this theory to the results shown in Figure 7, at least one difference is apparent, namely, the increased relative loss in weight of the white iron to the steels at the higher pressure. It appears logical, therefore, to reason that the severity of the test is still not great enough to bring out the differences in resistance to wear inherent in all the materials tested.

The sharpness of the sand is also of importance in determining the rates of wear of materials. It should be noted from results shown in Figures 5 and 7 that when the sand blast was used as the abrading medium, sharp sand (Illinois glass) produced rates of wear which were about four times those obtained on similar specimens tested with larger and more rounded sand (Ottawa) at constant pressure.

These results show that many factors affect the rates of wear with this type of test, so it would be expected that slight changes in actual conditions of service would affect the rates of wear of materials considerably.

\section{BRINELL TEST}

\section{(a) SELECTION OF SAND}

The sand used as the abrading medium in the Brinell test was Mlinois glass sand ${ }^{6}$ passed through a sieve of $0.297 \mathrm{~mm}$. opening. It was found necessary to sieve this sand because of its variation in grain size. This size of sand was considerably smaller, incidentally, than the size used by Brinell who recommended a grain size of 0.2 to $0.8 \mathrm{~mm}$. The use of sand of such wide limits in size introduces a variable which must be eliminated in order to secure definitely reproducible data.

To determine whether or not the sand used should be dried, a series of tests was made on cold-rolled steel with the sand as sieved and also as sieved and dried for 24 hours at $105^{\circ}$ to $110^{\circ} \mathrm{C}$. The results of these tests are shown in Table 3.

- Furnished through the courtesy of the Tavern Rock Sand Co., Toledo, Ohio. 


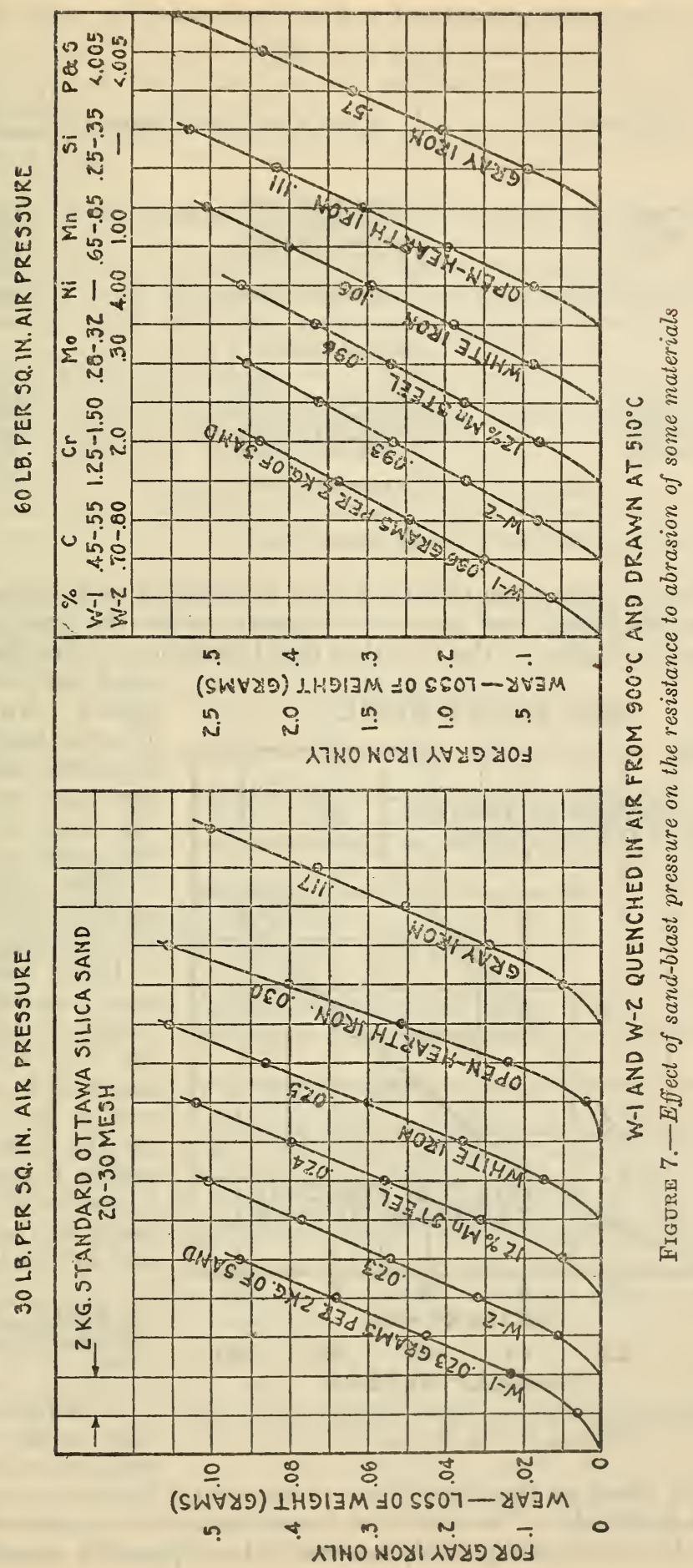


TABLE 3.-Comparison of dried and undried sand as abrasives in the Brinell test SAND NOT DRIED

\begin{tabular}{|c|c|c|c|}
\hline Duration of test & Weight of sand passed through & $\begin{array}{l}\text { Loss of } \\
\text { weight }\end{array}$ & "Nm"No. \\
\hline $\begin{array}{l}4 \text { minutes } 92 / 5 \text { seconds } \\
4 \text { minutes } 10 \text { seconds } \\
44 \text { minutes } 11 \text { seconds } \\
4 \text { minutes } 18 \text { seconds. }\end{array}$ & 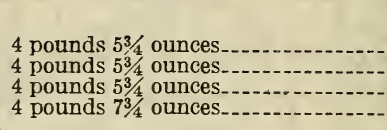 & $\begin{array}{l}g \\
0.1501 \\
.1443 \\
.1471 \\
.1528\end{array}$ & $\begin{array}{l}190 \\
207 \\
201 \\
196\end{array}$ \\
\hline Average 4 minutes 12 seconds.- & 4 pounds $61 / 4$ ounces.- & .1486 & 198 \\
\hline
\end{tabular}

SAND AS DRIED

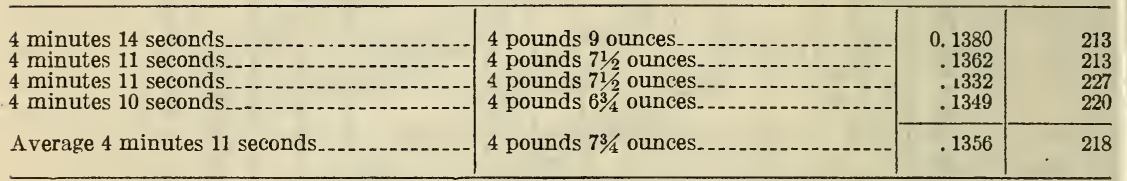

Length of test run was $60 \mathrm{~m}$ and the pressure used was $10 \mathrm{~kg}$.

Excellent checks were obtained with both dried and undried sand. The amount of sand used per test was greater when the dried sand was used, due, no doubt, to the fact that dried sand flows more freely than

\section{COLD ROLLED STEEL}

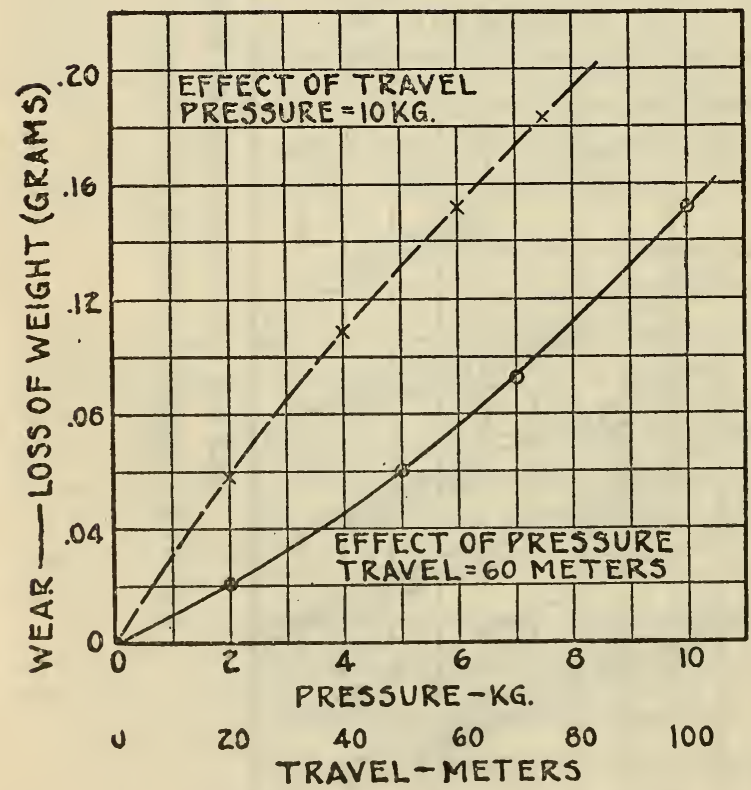

Fiatre 8.-Effect of pressure and distance traveled by abrading disk in Brinell test sand with some contained moisture. Despite the fact that a greater amount of dry sand was used, the loss of weight was greater with the smaller amount of undried sand used in the tests. Since a large volume of sand was sieved and stored, and since drying the sand under controlled methods would have slowed up the work considerably, it was decided to make all tests by using the sand without artificial drying.

(b) EFFECT OF PRESSURE AND OF DISTANCE TRAVELED BY DISK

A series of tests was made on coldrolled steel to determine the effect of the variables-pressure and distance traveled by the abrading disk. The results of these tests are summarized in Figure 8. As would be expected, increase in total pressure caused a more 
rapid loss of weight because of the greater proportional increase in pressure per unit of area, while increase in travel caused a smaller increase in loss of weight due to the decreasing average pressure per unit of area during the test (greater area of contact). For test purposes it was decided to make all runs at a pressure of $10 \mathrm{~kg}$ and $60 \mathrm{~m}$ travel of the disk.

\section{(c) EFFECT OF CARBON CONTENT ON THE RESISTANCE TO WEAR}

A series of steels varying in carbon content was tested as normalized, as normalized and annealed, and as normalized and hardened, to determine the effect of carbon content on resistance to wear. These results are summarized in Figure 9 together with the determinations of Rockwell and Brinell hardness. All points on the curves of wear are the average of four tests. The chemical compositions and heat treatments of these steels are given in Table 4.

TABLE 4.-Compositions of the steels

\begin{tabular}{|c|c|c|c|c|c|c|c|c|}
\hline \multirow{2}{*}{ Mark } & \multirow[b]{2}{*}{$\mathrm{C}$} & \multirow[b]{2}{*}{$\mathrm{Mn}$} & \multirow[b]{2}{*}{$\mathrm{P}$} & \multirow[b]{2}{*}{$\mathbf{S}$} & \multirow[b]{2}{*}{$\mathrm{Si}$} & \multicolumn{3}{|c|}{ Temperature- } \\
\hline & & & & & & $\begin{array}{c}\text { Normal- } \\
\text { jzing }\end{array}$ & $\begin{array}{c}\text { Harden- } \\
\text { ing }\end{array}$ & $\begin{array}{c}\text { Anneal- } \\
\text { ing }\end{array}$ \\
\hline 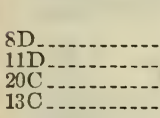 & $\begin{array}{r}\text { Per cent } \\
0.078 \\
.203 \\
.425 \\
.573\end{array}$ & $\begin{array}{r}\text { Per cent } \\
0.482 \\
.430 \\
.673 \\
.700\end{array}$ & $\begin{array}{r}\text { Per cent } \\
0.099 \\
.006 \\
.044 \\
.013\end{array}$ & $\begin{array}{r}\text { Per cent } \\
0.083 \\
.041 \\
.026 \\
.023\end{array}$ & $\begin{array}{r}\text { Per cent } \\
0.018 \\
.027 \\
.223 \\
.200\end{array}$ & $\begin{array}{l}{ }^{\circ} C . \\
970 \\
940 \\
865 \\
830\end{array}$ & $\begin{array}{r}{ }^{\circ} C . \\
940 \\
910 \\
835 \\
800\end{array}$ & $\begin{array}{l}{ }^{\circ} \mathrm{C} . \\
920 \\
890 \\
815 \\
780\end{array}$ \\
\hline $\begin{array}{l}34 \mathrm{~A} \\
\text { EU } \\
35 \mathrm{~A} \\
51\end{array}$ & $\begin{array}{l}.762 \\
.81 \\
1.03 \\
1.29\end{array}$ & $\begin{array}{l}.501 \\
.23 \\
.345 \\
.271\end{array}$ & $\begin{array}{l}.028 \\
.024 \\
.037 \\
.011\end{array}$ & $\begin{array}{l}.026 \\
.021 \\
.036 \\
.013\end{array}$ & $\begin{array}{l}.276 \\
.28 \\
.387 \\
.250\end{array}$ & $\begin{array}{l}810 \\
810 \\
810 \\
925\end{array}$ & $\begin{array}{l}775 \\
780 \\
770 \\
770\end{array}$ & $\begin{array}{l}755 \\
755 \\
755 \\
755\end{array}$ \\
\hline
\end{tabular}

All specimens were about one-fourth inch thick.

Time of holding at all temperatures, one-half hour.

All hardening by water quenching.

All specimens hardened or annealed were previously normalized.

The "Nm" wear-resistance numbers of these steels were very erratic for reasons previously mentioned and are considered of little value.

If the losses of weight of these steels are considered, it is evident that the percentage of carbon exerted a very marked influence upon the resistance to wear. An increase of carbon increased resistance to wear and this increase was greater in the lower range of carbon content than in the higher range. Furthermore, the resistance to wear of the hardened steels was greater than that of the normalized steels, which, in turn, showed greater resistance than the annealed steels. Comparing these trends with the curves of hardness shows in a convincing manner that the resistance to wear of carbon steels as determined by the Brinell machine is dependent upon the hardness.

The only point which is radically off the weight-loss curves is that for the annealed, 0.81 per cent carbon steel. It will be noted that the hardness of this steel was between the corresponding values for the 0.42 per cent and 0.57 per cent carbon steels and that the loss of weight also was between the corresponding losses of weight of these two steels. Thus, a decreased hardness was reflected by an increased loss of weight. Similarly, the normalized, 0.76 per cent 


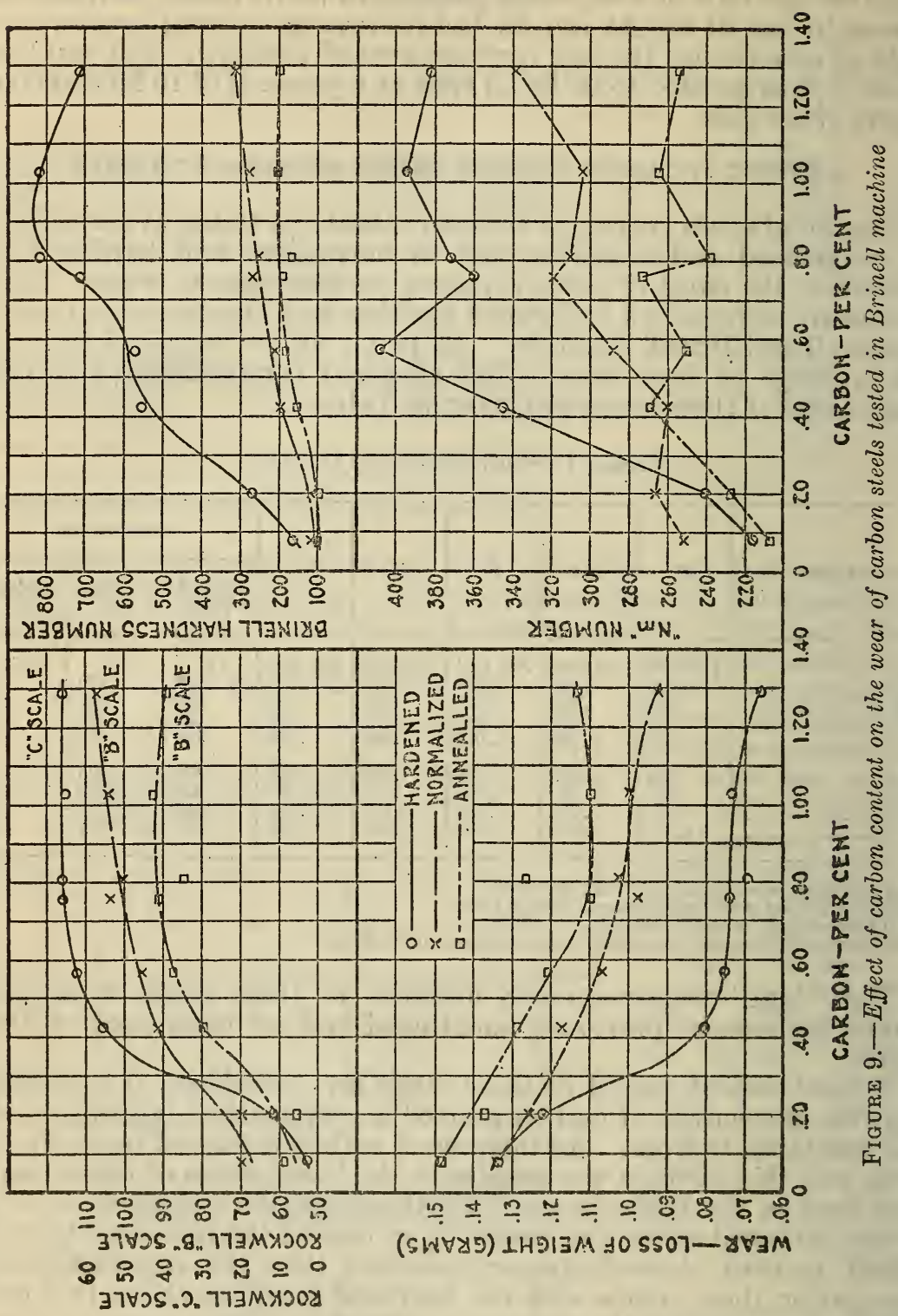




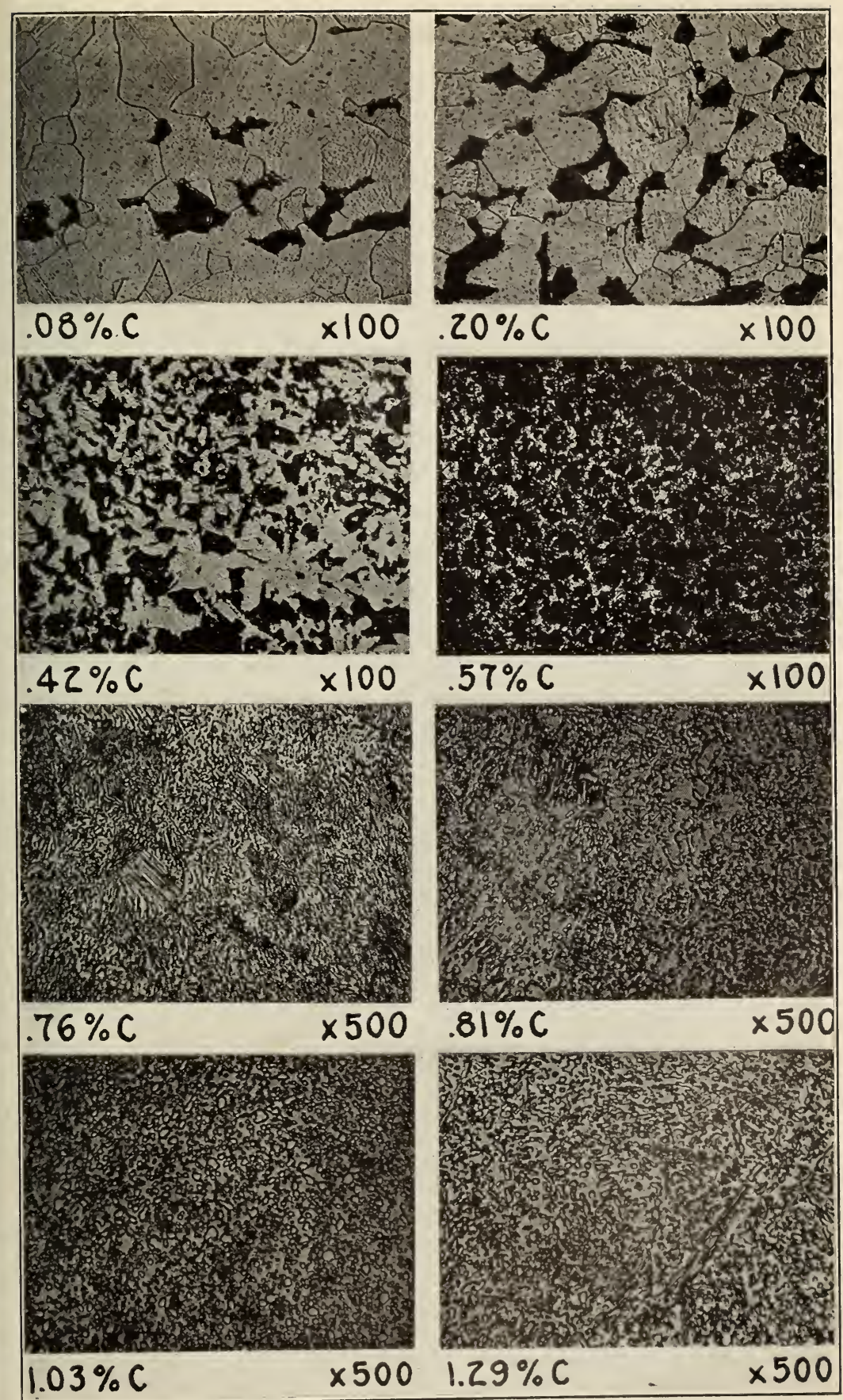

FIGURE 10.-Microstructures of annealed carbon steels tested in Brinell machine Etched with 5 per cent picric acid in alcohol. 


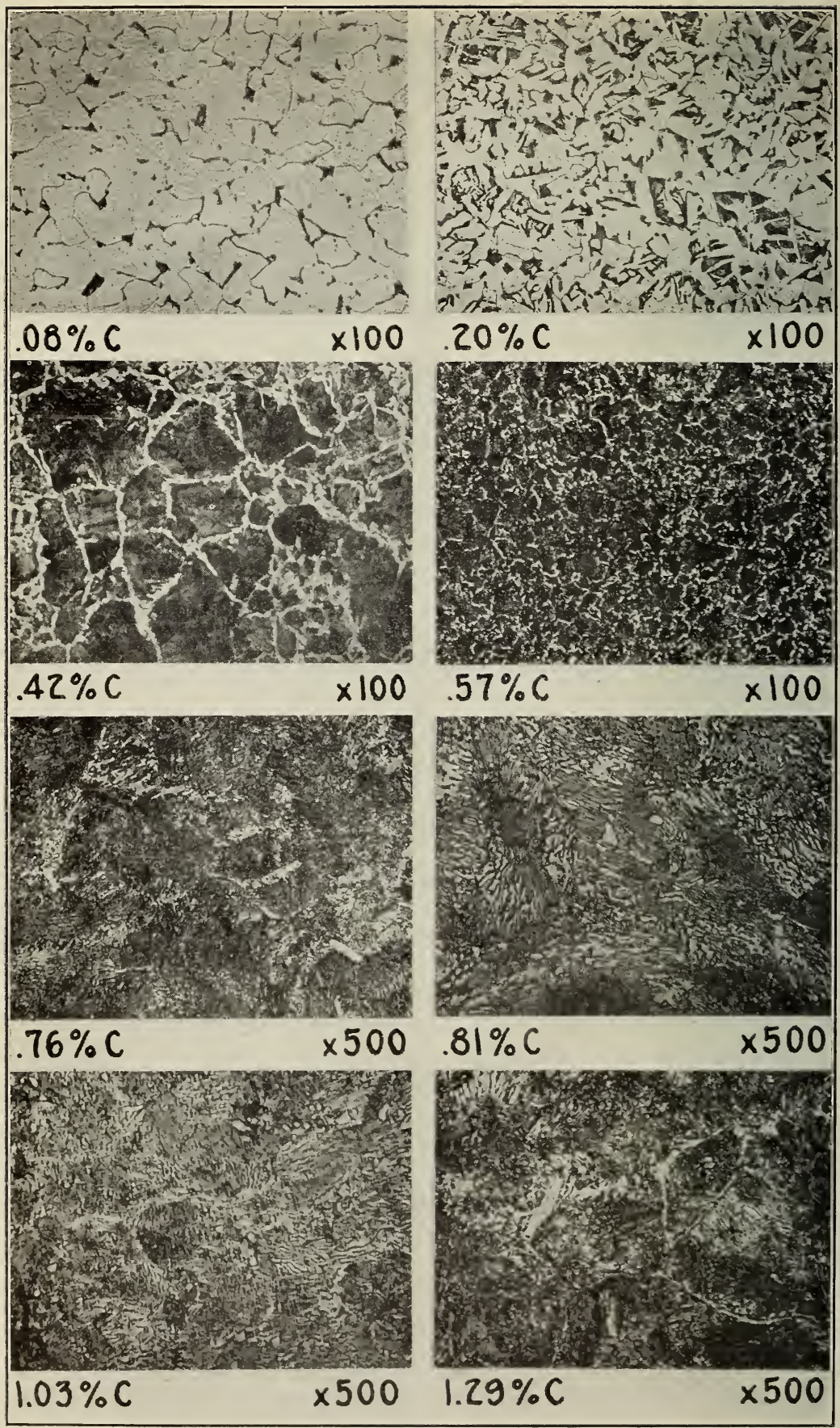

Figure 11.-Microstructures of normalized carbon steels tested in Brinell machine 
carbon steel showed a slightly higher hardness as judged by the curve of hardness and this was refiected by a decreased loss of weight.

The microstructures of the annealed steels are shown in Figure 10, of the normalized steels in Figure 11, and of the hardened steels in Figure 12.

$.81 \%$ C STEEL, WATER Q. FROM $780^{\circ} \mathrm{C}$

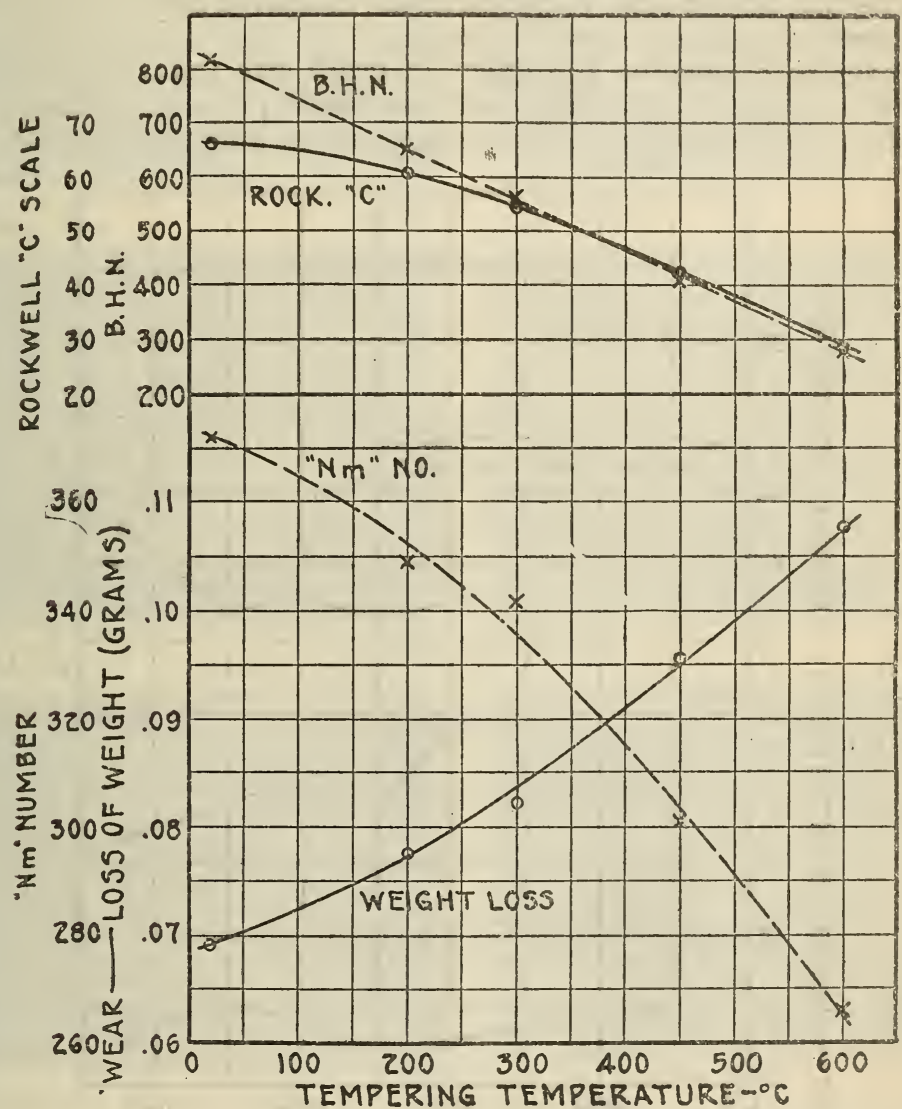

FIGURE 13.-Effect of tempering temperature on the wear of an 0.81 per cent carbon steel tested in Brinell machine

(d) EFFECT OF TEMPERING TEMPERATURE ON THE RESISTANCE TO WEAR

The effect of tempering temperature on the resistance to wear of the 0.81 per cent carbon steel was studied. All specimens were held for one hour at tempering temperature. The results of the tests (each point is the average of four tests), together with the hardness determinations, are summarized graphically in Figure 13. These curves show that increase in tempering temperature progressively lowers the resistance to wear of eutectoid carbon steel as determined by the Brinell machine.

'The microstructures of these steels are shown in Figure 14.

$$
4754^{\circ}-30-5
$$


(e) EFFECT OF ANNEALING TEMPERATURE ON THE RESISTANCE TO WEAR

There is a popular conception to the effect that the smaller the grain size of the steel, the greater the resistance to wear. This idea seems to be based, at least in part, upon the assumption that the larger the grain size, the more brittle the material and the more easily the individual grains may be torn out. As will be shown later in this report, in the type of abrasion investigated here the individual grains are not torn out as whole grains.

In order to determine the effect of grain size upon the resistance to wear, two steels ( 0.20 per cent and 0.76 per cent carbon) were annealed at successively higher temperatures and then tested. The

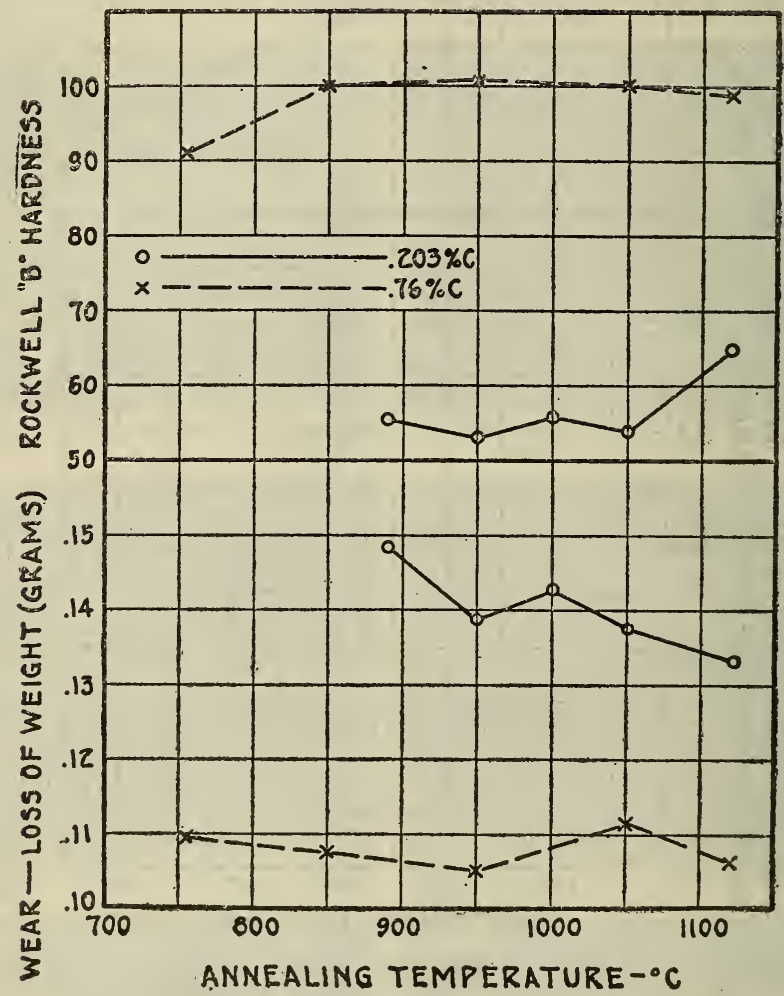

FrguRE 15.-Effect of annealing temperature on the wear of a 0.20 per cent and 0.76 per cent carbon steel tested in Brinell machine

samples were held one-half hour at each annealing temperature with the exception of the highest temperature, at which they were held for three and three-fourths hours. The results of these tests are summarized in Figure 15.

The effect of the temperature of annealing upon the resistance to wear of the 0.76 per cent carbon steel was very slight, but the effect on the 0.203 per cent carbon steel of increasing the temperature of annealing was rather marked, the resistance to wear increasing with the temperature. This is the reverse of what ordinarily would have been expected and no explanation of this apparent anomaly is offered. 


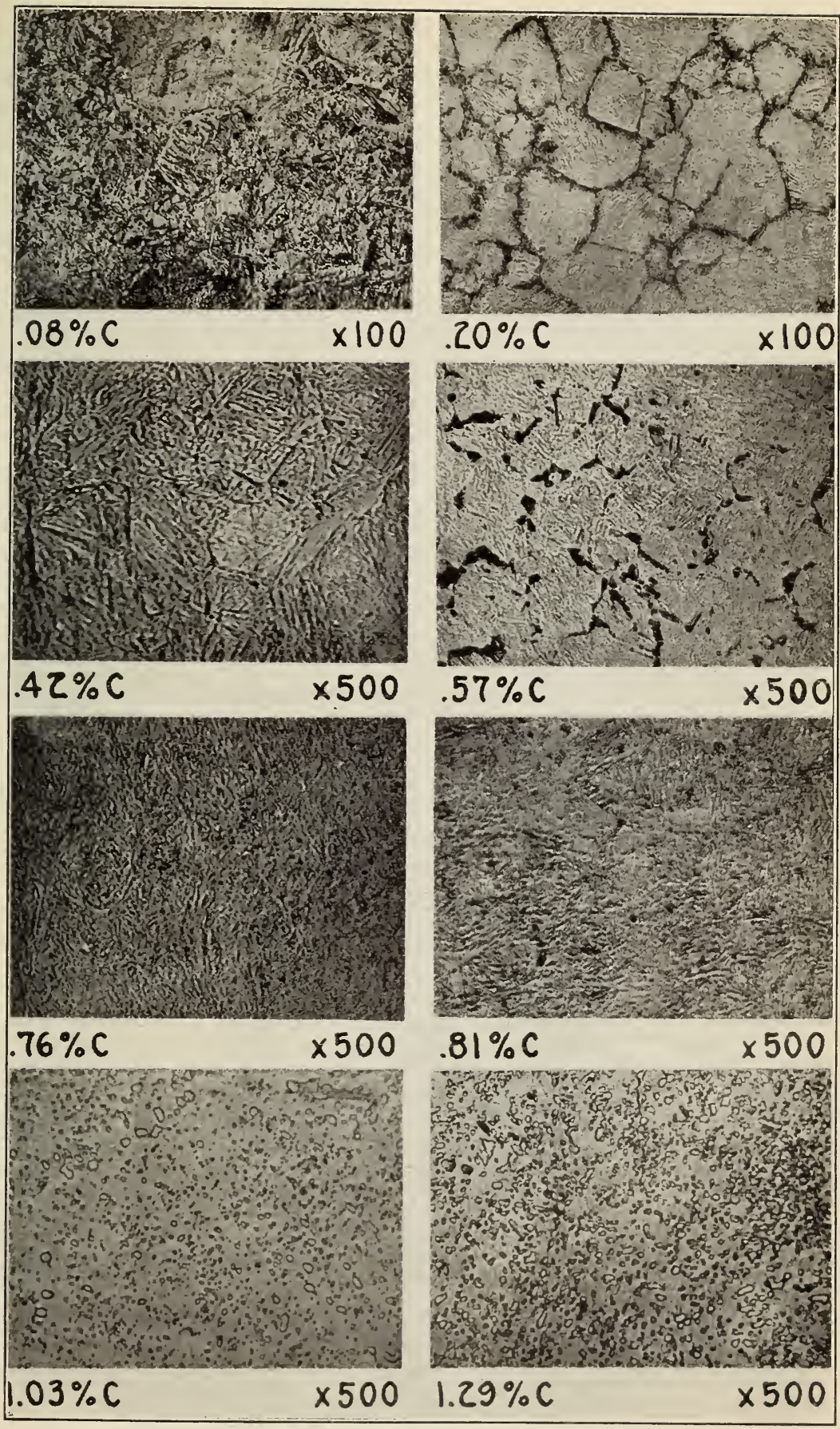

FIGURE 12.-Microstructures of hardened carbon steels tested in Brinell machine Etched with 5 per cent picric acid in alcohol. 


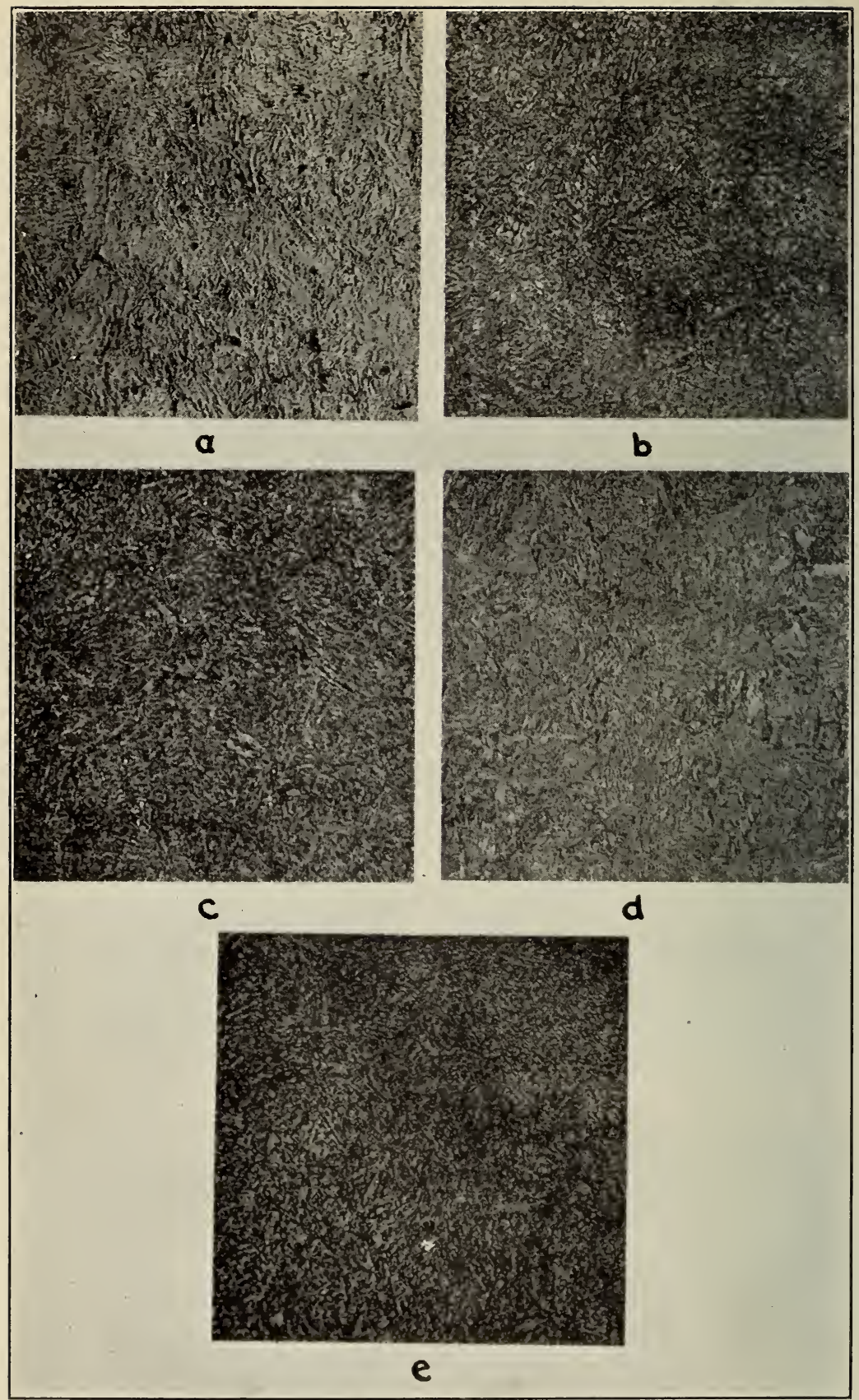

Figure 14.-Microstructures of a tempered 0.81 per cent carbon steel tested in Brincll machine

Etched with 5 per cent picric acid in alcohol. $\times 500$. $a, \Delta$ s hardened; $b$, tempered at $200^{\circ} \mathrm{C}$; $c$, tempered at $300^{\circ} \mathrm{C}$; $d$, tempered at $450^{\circ} \mathrm{C}$; $e$, tempered at $600^{\circ} \mathrm{C}$. 


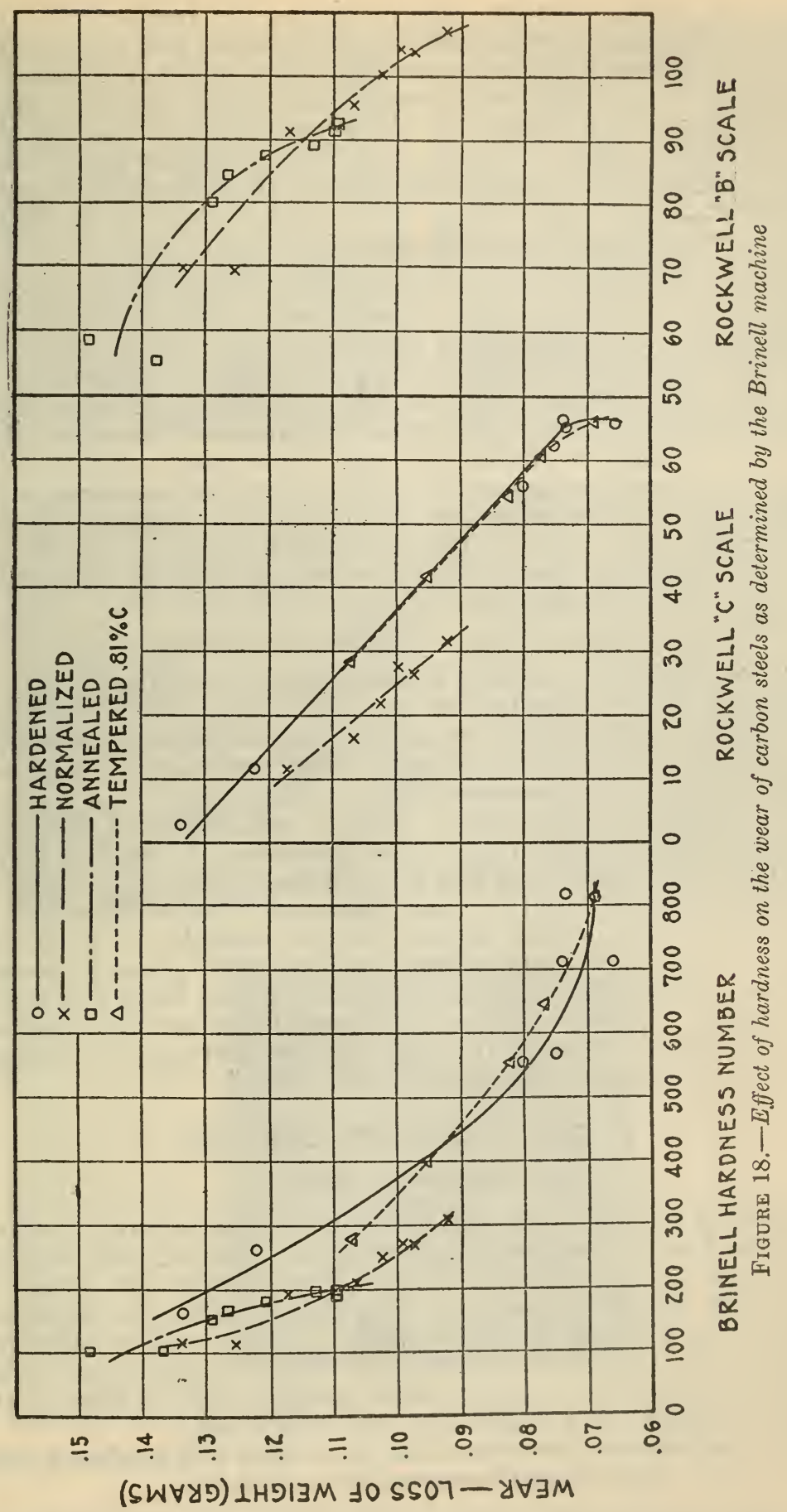


It may be noted, however, that increasing the temperature of annealing results in a trend toward higher hardness, and this is a factor in causing increased resistance to wear. The microstructures of the 0.203 per cent carbon steel, annealed at various temperatures, are shown in Figure 16 and of the 0.76 per cent carbon steel in Figure 17. The increase in grain size is not so marked as might have been expected, but the trend toward larger grains with increasing temperature is unmistakable.

\section{(f) RELATION OF HARDNESS TO RESISTANCE TO WEAR}

The fact that the wear as determined by the Brinell machine is influenced by the hardness has already been mentioned. In Figure 18 the data shown in Figures 9 and 13 have been replotted to show the effect of hardness on the loss of weight of the various carbon steels. These curves show that for increased hardness, the losses of weight decrease; that is, the resistance to wear increases. This relationship is practically linear in the lower range of hardness numbers; in the higher range, however, apparently large changes in hardness are not accompanied by correspondingly great changes in resistance to wear. This may be due to the fact that the Brinell hardnesses of the hard steels were found to be unduly high, caused, perhaps, by the difficulty of reading accurately small Brinell impressions.

\section{(g) EXAMINATION OF ABRADED SURFACES}

In order to show the manner in which wear takes place on abraded surfaces, the groove worn into an annealed 0.20 per cent carbon steel was copper plated, and both cross sections and longitudinal sections were cut for microscopic examination. The structures of these samples at the wearing surfaces are shown in Figure 19.

The appearance of the surface both at right angles to the groove and longitudinally through it is about the same. In both cases very marked evidence of localized flow in the form of strain lines is present. This has also been found in wear-resistance tests of bronzes. ${ }^{7}$ An examination of the abraded surface (see, for example, fig. $19(b)$ ) also reveals the fact that the mechanism of wear takes place by parts of individual grains being abraded and not by grains being removed in their entirety. This is what would be expected when it is considered that at room temperatures the cohesive force between the grains is greater than the internal strength of the grains:

\section{DISCUSSION OF RESULTS}

\section{BALL-MILL TEST}

The resultis obtained with the ball mill were quite erratic and will he dismissed as of qualitative value only. The ball mill does not seem to hold much promise as a laboratory machine for testing the resistance of metals to abrasion. The trouble with this machine is twofold-it is not sufficiently sensitive to show positive differences in resistance to wear and it is not sufficiently accurate to give check results. In addition to these disadvantages the making of the spherical specimens is a costly and tedious process.

These tests showed, however, that the forged and hardened specimens lost less weight than the normalized specimens.

H. J. French, S. J. Rosonberg, W. LeC. Harbaugh, and H. C. Cross, Wear and Mechanical Properties of Railroad Bearing Bronzes at Different Temperatures, B. S. Jour. Research, 1 (RP13); September, 1928. 


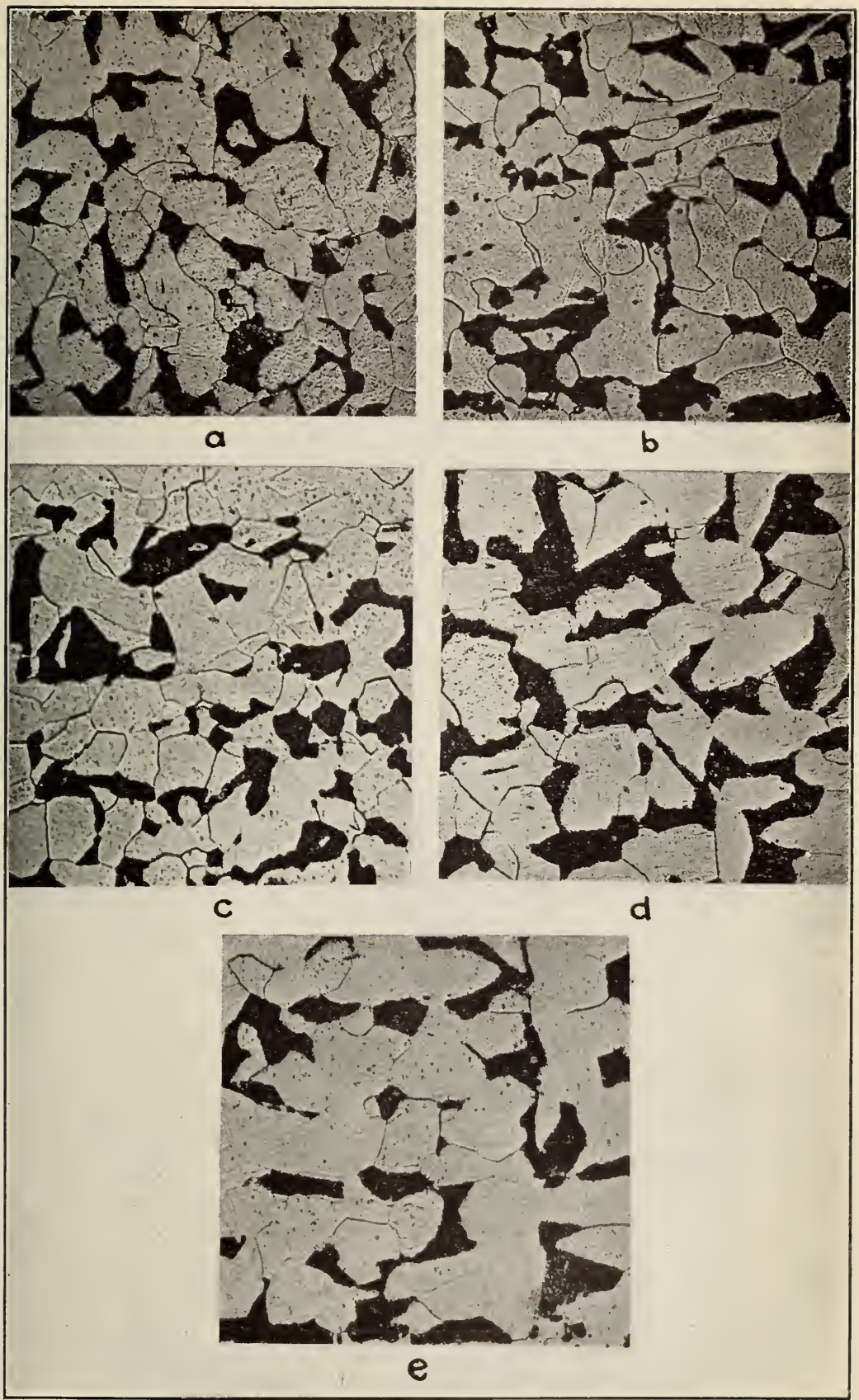

FiguRE 16.-Microstructures of 0.20 per cent carbon steel annealed at different temperatures, tested in Brinell machine

Etched with 5 per cent picric acid in alcohol. $\times 100$. $a$, Annealed at $890^{\circ} \mathrm{C}$. for one-half hour $b$, annealed at $950^{\circ} \mathrm{C}$. for one-half hour; $c$, annealed at $1,000^{\circ} \mathrm{C}$. for one-half hour; $d$, annealed at $1,050^{\circ} \mathrm{C}$. for one-half hour; $e$, annealed at $1,120^{\circ} \mathrm{C}$. for three and three-fourths hours. 


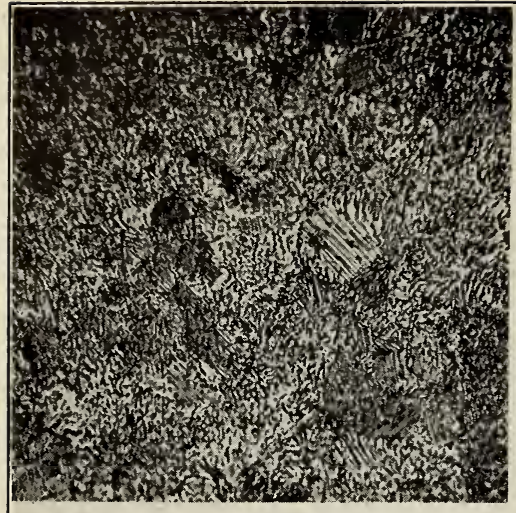

a

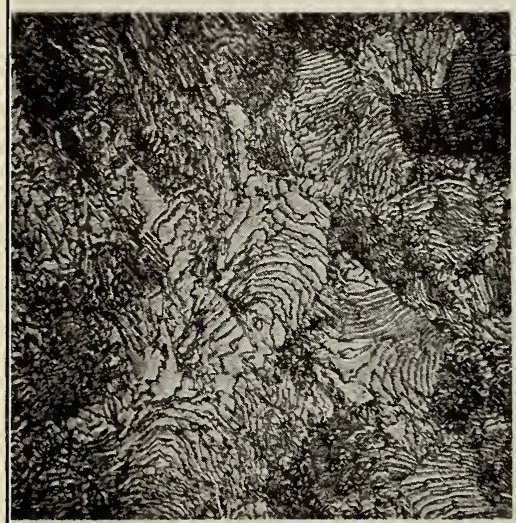

C

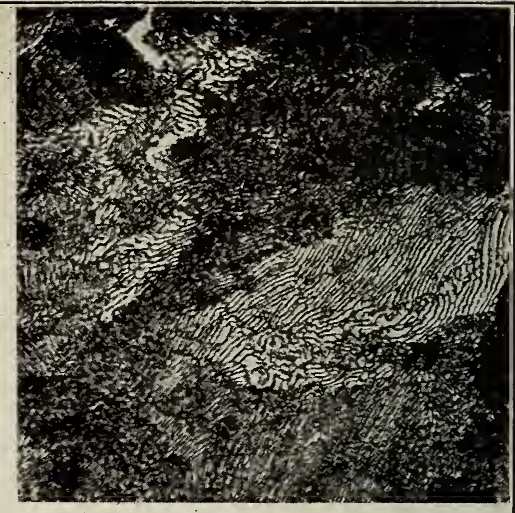

b

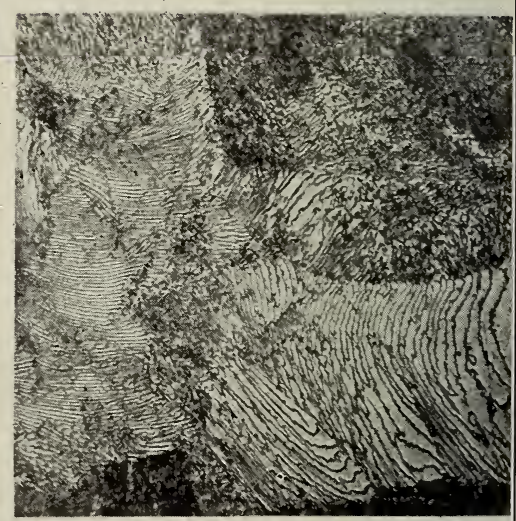

d

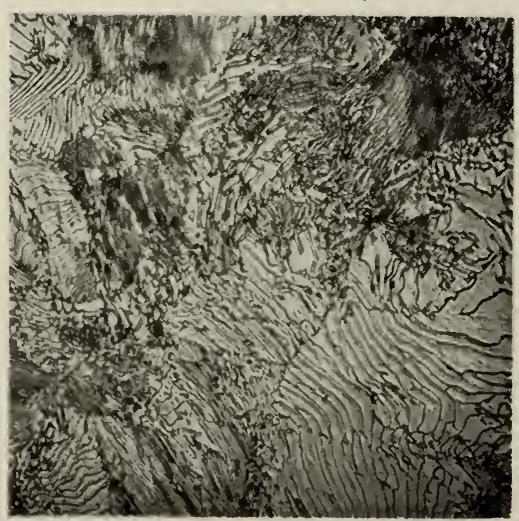

e

FIGURE 17.-Microstructures of 0.76 per cent carbon steel annealed at different temperatures, tested in Brinell machine

Etched with 5 per cent picric acid in alcohol. $\times 500, a$, Annealed at $755^{\circ} \mathrm{C}$. for one-half hour; $b$, annealed at $850^{\circ} \mathrm{C}$. for one-half hour; $c$, annealed at $950^{\circ} \mathrm{C}$. for one-half hour; $d$, annealed at $1,050^{\circ} \mathrm{C}$. for one-half hour; $e$, annealed at $1,120^{\circ} \mathrm{C}$. for three and three-fourths hours. 


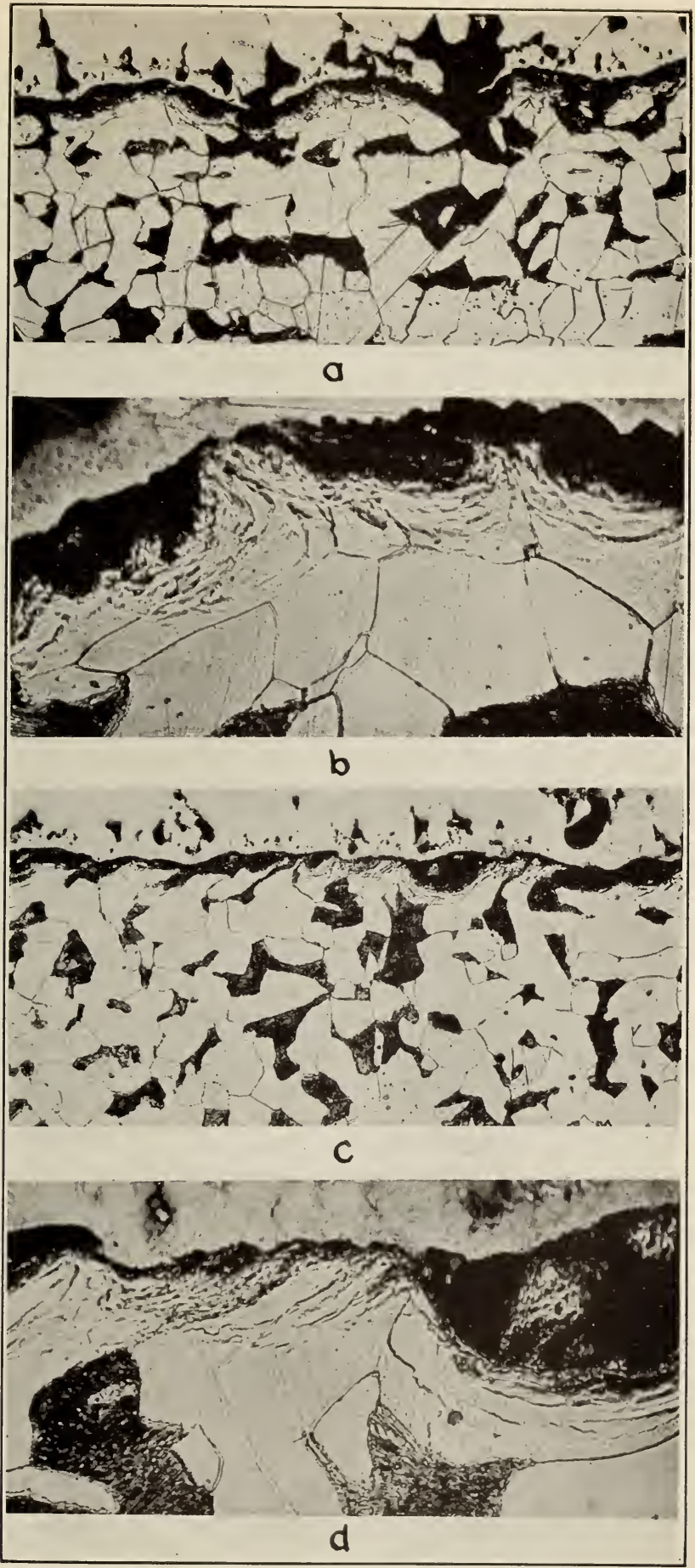

FIgURE 19.-Micrographs of the structure adjacent to the abraded surface of an annealed 0.20 per cent carbon steel tested in Brinell machine

Etched with 2 per cent nitric acid in alcohol. $a$, Cross section through bottom of groove. $\times 100 ;, b$, same. $\times 500 ; c$, longitudinal section through bottom of groove. $\times 100 ; d$, same. $\times 500$. 


\section{SAND-BLAST TEST}

The sand blast is a very rapid and accurate abrading medium. Of all the steels tested, however, no great differences were apparent between them. Practically the same rates of wear were obtained, for instance, on the same steel when normalized as were obtained. when hardened. It is thought that this apparent lack of sensitivity was due to the fact that the abrading conditions were not suficiently severe to bring out the inherent differences in wear characteristic of the materials tested. This opinion is based upon the fact that differences in resistance to wear between some materials were apparent at a blasting pressure of $60 \mathrm{lbs} . / \mathrm{in}^{2}{ }^{2}$ that were not noticeable at a pressure of $30 \mathrm{lbs} . / \mathrm{in} .^{2}$.

\section{BRINELL TEST}

A series of carbon steels varying from 0.08 to 1.29 per cent carbon. was tested in the normalized, annealed, and hardened conditions. The results of these tests showed that the resistance to wear of these steels in this special type of test was dependent upon the hardness. $\Lambda$ study of the effect of tempering temperature upon the wear showed the same trend; that is, the resistance to wear increased with the hardness.

The effect of grain size upon the resistance to wear was studied by testing a 0.20 per cent and a 0.76 per cent carbon steel annealed at various temperatures. An increase in temperature of annealing resulted in a general increase in resistance to wear, as evidenced by a decreased loss of weight, this being more marked in the low-carbon steel than in the high-carbon steel.

A study of the mechanism of wear or abrasion showed that grains of the steel were not torn off in their entirety, but were worn away in small particles, the abrasion being accompanied by severe local straining.

\section{SUMIMARY AND CONCLUSIOINS}

Three devices for testing the resistance of metals to abrasion were studied - the ball mill, the sand blast, and the Brinell machine.

The ball mill proved to be very unsatisfactory, only qualitative results being obtained. Generally speaking, this type of test showed. hardened steels to be somewhat more resistant to abrasion than the same steels in the normalized condition.

The sand blast proved to be a very rapid and accurate abrading medium, but failed to differentiate between many steels which were known to have widely different wear characteristics in different conditions of service. This apparent anomaly seems to be due to the fact that the abrasion was not sufficiently severe to bring out the differences in resistance to wear inherent in the stcel and shows conclusively that slight modifications of test conditions will give different results on the resistance of different materials to wear.

The Brinell test showed that the resistance to wear of normalized, annealed, hardened, or tempered carbon steels increased with an increase in hardness. Increasing the temperature of annealing resulted in a slight increase in resistance to wear, the increase being more marked in a low-carbon than in a high-carbon steel.

Abrasion in this last type of test is caused by the wearing away of exposed sections of the individual grains and not by the removal 
of the grains in their entirety. The abrasion is accompanied by severe local straining due to cold working.

As slight variables in wear testing have been shown to give different results, it should not be expected that wear-resistance tests made on machines of this type will necessarily check special service conditions where many variables are encountered.

\section{ACKNOWLEDGMENTS}

The author is indebted to Dr. R. L. Dowdell, senior metallurgist, for his kindly suggestions and criticisms, and to Houston Babb, junior scientific aid, for his conscientious assistance in many of the tests.

Washington, April 18, 1930. 